\title{
Preliminary study on the influence of Octane Sensitivity on knock statistics in a GDI engine.
}

\author{
Francesco Cicci ${ }^{\mathrm{a}, *}$, prof. Ing. Giuseppe Cantore ${ }^{\mathrm{a}}$ \\ a) Department of Engineering "Enzo Ferrari”, University of Modena and Reggio Emilia, Via Vivarelli \\ 10, Modena 41125, Italy \\ * Corresponding author: francesco.cicci@unimore.it
}

\begin{abstract}
In the 3D-CFD practice, actual gasoline fuels are usually replaced by surrogate blends composed of Iso-Octane, n-Heptane and Toluene (Toluene Reference Fuels, TRFs). In this work, the impact of surrogate formulation on the probability of end-gas auto-ignition is investigated in a single cylinder engine. CFD simulations are run on equal charge stratification to discern the effect of fuel reactivity from that of evaporation and mixing. Blends are formulated using an internal methodology, coupled with a proprietary method to predict knock statistical occurrence within a RANS framework. Chemical kinetics calculations of Ignition delay times are performed in a $0 \mathrm{D}$ constant pressure reactor using a mechanism for gasoline surrogates, proposed by the Clean Combustion Research Center of King Abdullah University of Science and Technology (KAUST), consisting of 2406 species and 9633 reactions. Surrogates mimic a commercial European gasoline (ULG95). Five different formulations are presented. Three are characterised by equal RON (95) with progressively decreasing Octane Sensitivity $S$. The fourth and the fifth have a sensitivity of 10 but with lower RON (92.5 and 90). The combinations allow the reader to separate the effects of octane sensitivity from those of RON quality of the tested fuels. Applying the different surrogates, changes in each of autoignition phasing, magnitude and statistical probability are investigated. Results confirm the dependency of knock occurrence on the Octane Sensitivity, as well as the need to include engine-specific and operationspecific characteristics in the analysis of knock. The Octane Index (OI) formulation developed by Kalghatgi is discussed.
\end{abstract}

\section{Introduction}

Knock is a complex phenomenon which depends on fuel chemistry, combustion chamber design and engine operating conditions. Nowadays, it represents a major barrier on the performance of spark-ignition engines [1]. Most modern SI engines are knock-limited in at least some portions of their operating range. When knock is detected, the engine control system introduces corrective actions to prevent and/or mitigate knock, which inevitably lead to degradation of engine performance and/or efficiency. Thus, the anti-knock quality of the fuel affects engine performance. It is usually expressed by the Research Octane and Motor Octane Numbers, according to the ASTM procedures. It has long been known that RON or $M O N$ alone do not fully describe the knocking behaviour of a practical fuel in an engine. For instance, knock intensity depends on fuel composition (e.g aromatic and oxygenates contents), as well as on engine speed and, broadly speaking, on combustion characteristics. 
These must be thoroughly understood in order to face economical, technological, and societal challenges [2]. Kalghatgi [3,4] synthesized all of these contributions using the Octane Index to express the link between engine-related and fuel-related parameters. Following previous studies $[5,6,7,8,9,10]$, in the present paper the authors run virtual experiments of a GDI engine operated at 2000 RPM fuelled with five surrogates, purposely built $[11,12]$ to span a wide range of anti-knock characteristics using a state-of-the-art gasoline chemical kinetics model [13]. In particular, an original statical knock model is here adopted and it is briefly recalled.

\section{Fuel surrogate methodology and evaluation of mixture reactivity}

In [11] Del Pecchia et al. introduced a methodology to formulate gasoline fuel surrogates to emulate the most relevant chemical properties of a commercial gasoline, namely the autoignition and the flame propagation characteristics. The same authors recently demonstrated the need of a proper number of pure components to simultaneously match multiple key aspects of a given fuel [12]. While the methodology shows all its potentiality when characteristics of the reference gasoline are available in details (RON, MON, EPIONA spectrum) it can be used also in case of fragmented information. A simplified version of the methodology is here adopted targeting RON and MON only. The following subset of the complete system presented in [11] is adopted.

$$
\left\{\begin{aligned}
\sum_{i=1}^{n} x_{i} & =1 \\
\sum_{i=1}^{n} x_{i} \cdot R O N_{i} & =R O N_{F U E L} \\
\sum_{i=1}^{n} x_{i} \cdot M O N_{i} & =M O N_{F U E L}
\end{aligned}\right.
$$

Where $x_{i}, R O N_{i}, M O N_{i}$ are the molar fraction, $R O N$ and $M O N$ values of the $i_{t h}$ pure component respectively; using a TRF surrogate, the above linear system provides a unique solution, in the case of $\mathrm{n}$ equal to three. Bearing in mind the limitations arising from the use of very simple 3-component fuel blends, five surrogates are then generated whose characteristics are summarized in Table 1[A].

\begin{tabular}{|c|c|c|c|c|c|c|c|c|}
\hline \multicolumn{5}{|c|}{ SURROGATE MIXTURE [\%MASS] } & & & & \\
\hline \multirow{3}{*}{ 岁 } & $\mathrm{C} 8 \mathrm{H} 18$ & 63.21 & RON & 95 & & & & \\
\hline & $\mathrm{C} 7 \mathrm{H} 16$ & 10.46 & MON & 90 & & & & \\
\hline & $\mathrm{C} 7 \mathrm{H} 8$ & 26.33 & LHV $[\mathrm{MJ} / \mathrm{kg}]$ & 43.28 & & & & \\
\hline \multirow{2}{*}{$\begin{array}{l}\text { 号 } \\
\hat{\delta} \\
\text { p. }\end{array}$} & $\mathrm{C} 8 \mathrm{H} 18$ & 45.22 & RON & 95 & \multicolumn{4}{|c|}{ Look-Up Tables } \\
\hline & $\begin{array}{r}\mathrm{C} 7 \mathrm{H} 16 \\
\mathrm{C} 7 \mathrm{H} 8\end{array}$ & $\begin{array}{l}13.82 \\
40.96\end{array}$ & $\begin{array}{rl}\mathrm{MON} & \mathrm{LHV}[\mathrm{MJ} / \mathrm{kg}]\end{array}$ & $\begin{array}{r}87.5 \\
42.70\end{array}$ & PARAMETER & $\mathrm{MIN}$ & MAX & STEPPING \\
\hline \multirow{3}{*}{ 品 } & $\mathrm{C} 8 \mathrm{H} 18$ & 26.85 & RON & 95 & Pressure [bar] & 5 & 150 & 5 \\
\hline & $\mathrm{C} 7 \mathrm{H} 16$ & 17.43 & MON & 85 & Temperature $[\mathrm{K}]$ & 500 & 1100 & 20 \\
\hline & $\mathrm{C} 7 \mathrm{H} 8$ & 56.72 & LHV $[\mathrm{MJ} / \mathrm{kg}]$ & 42.13 & Eq. Ratio [-] & 0.3 & 2 & 0.1 \\
\hline \multirow{3}{*}{$\begin{array}{l}m \\
\frac{0}{5} \\
\frac{0}{m}\end{array}$} & $\mathrm{C} 8 \mathrm{H} 18$ & 23.03 & RON & 92.5 & EGR [\%] & 0 & 10 & 5 \\
\hline & $\mathrm{C} 7 \mathrm{H} 16$ & 20.04 & MON & 82.5 & & & & \\
\hline & $\mathrm{C} 7 \mathrm{H} 8$ & 56.93 & LHV $[\mathrm{MJ} / \mathrm{kg}]$ & 42.13 & & & & \\
\hline \multirow{3}{*}{$\begin{array}{l} \\
0 \\
\frac{1}{5} \\
0\end{array}$} & $\mathrm{C} 8 \mathrm{H} 18$ & 20.19 & RON & 90 & & & & \\
\hline & $\mathrm{C} 7 \mathrm{H} 16$ & 22.68 & MON & 80 & & & & \\
\hline & $\mathrm{C} 7 \mathrm{H} 8$ & 57.13 & LHV $[\mathrm{MJ} / \mathrm{kg}]$ & 42.13 & & & & \\
\hline \multicolumn{5}{|c|}{ [A] } & \multicolumn{4}{|c|}{ [B] } \\
\hline
\end{tabular}

Table 1: Formulated blend and their characteristics [A] and Look-Up Table range extension [B]. 
As visible, three of them (BS5, BS7.5 and BS10) match the actual RON value (95) of the reference gasoline, while a variable $M O N$ is targeted to achieve different $S$. The remaining two surrogates are formulated on equal $S(10)$ while targeting lower $R O N$ values, i.e. 92.5 and 90. Ignition delay calculations are then performed for each surrogate using DARS v2019.1, licensed by Siemens DISW, by means of a constant pressure reactor and a detailed chemical mechanism (2406 species and 9633 reactions) provided by the Clean Combustion Research Center at KAUST [13]. Delays are stored in Look-Up Tables (LUTs) for a wide range of pressures, temperatures, air index $(\lambda)$ and dilution rates, shown in Table 1 [B]. While $R O N$ is commonly used to identify the autoignition tendency of a given fuel, Kalghatgi demonstrated $[3,4]$ that in an engine-related context the attitude to auto ignite of actual fuels does not depend solely on the RON value. MON (and therefore octane sensitivity), air index, mixture thermodynamic state and engine speed must be considered. He proposed the Octane Index $(O I)$ as a reference parameter to define the anti-knock fuel quality for a given engine operating condition. $O I$ is expressed by:

$$
O I=R O N-K \cdot S
$$

Where $\mathrm{K}$ depends on the operating condition of the engine and it can be expressed as:

$$
K=0.00497 \cdot T_{\text {comp } 15}-0.135 \cdot \lambda-3.67
$$

where $\mathrm{T}_{\text {comp15 }}$ is the temperature $(\mathrm{K})$ when pressure reaches 15 bar during the compression stroke, $\lambda$ is the air-index $\left(A F R / A F R_{S}\right)$. In the specific case presented hereafter, a negative value of $K=-0.79$ is found for the investigated engine condition.

\section{Knock Modelling}

The stochastic nature of knock would suggest the use of Large Eddy Simulation (LES) in order to properly simulate the cyclic variability leading to sporadic end-gas auto ignition. However, LES requires high computational efforts and a statistically relevant number of simulated cycles $[14,15,16,17,18,19]$. A proprietary knock model proposed by the authors in $[8,9,20]$ combines the low computational cost of RANS equations with a statistical treatment of mixture reactivity to overcome the intrinsic limitations of ensembleaveraging. To this aim, two transport equations (Eq. 1-2) are added to compute mixture fraction $(Z)$ and unburnt temperature $\left(T_{u}\right)$ variance around in the CFD domain.

$$
\frac{\partial \rho Z^{\prime \prime}}{\partial t}+\frac{\partial}{\partial x_{j}}\left[\rho v_{j} Z^{\prime \prime}-\left(\rho D_{Z \prime \prime}+\frac{\mu_{t}}{\sigma_{t}}\right) \frac{\partial Z^{\prime \prime}}{\partial x_{j}}\right]=2 \frac{\mu_{t}}{\sigma_{t}}\left(\frac{\partial Z}{\partial x_{j}}\right)^{2}-c_{t} \rho \frac{\varepsilon}{k} Z^{\prime \prime}
$$




$$
\frac{\partial \rho T_{u}{ }^{\prime \prime}}{\partial t}+\frac{\partial}{\partial x_{j}}\left[\rho v_{j} T_{u}{ }^{\prime \prime}-\left(\rho D_{T_{u^{\prime \prime}}}+\frac{\mu_{t}}{\sigma_{t}}\right) \frac{\partial T_{u}{ }^{\prime \prime}}{\partial x_{j}}\right]=2 \frac{\mu_{t}}{\sigma_{t}}\left(\frac{\partial T_{u}}{\partial x_{j}}\right)^{2}-c_{t} \rho \frac{\varepsilon}{k} T_{u}^{\prime \prime}
$$

Details are described in [21]. Discrete autoignition delays for each $\left(Z-Z^{\prime \prime}<Z<Z+\right.$ $Z^{\prime \prime}, T_{u}-T_{u}^{\prime}<T_{u}<T_{u}+T_{u}^{\prime}$ ) combination are interpolated from the LUT, thus providing a distribution of in-cell reactivity; a 2-moments approach is then introduced to synthetize the statistical distribution of cell reactivities via a mean and a faster-than-average pair at each cell. Knock is triggered by the Livengood-Wu knock precursor $I=\int_{t_{0}}^{t} \widetilde{\omega} d t=\int_{t_{0}}^{t} \frac{1}{\tau} d t$; such approach is usually based on a unique cell-averaged ignition delay time $\tilde{\tau}=\tilde{\tau}\left(\tilde{p}, \widetilde{T_{u}}, \widetilde{\phi_{1}}, \widetilde{Y_{E G R}}\right)$, which is calculated either using empirical correlations or using a look-up table approach [22]. Following the availability of mean and faster than average reactivities, two distinct Livengood-Wu integral distributions are computed, $I=\int_{t_{0}}^{t} \widetilde{\omega} d t=\int_{t_{0}}^{t} \frac{1}{\tau} d t$ and $I^{\prime}=$ $\int_{t_{0}}^{t} \omega^{\prime} d t=\int_{t_{0}}^{t} \frac{1}{\tau \prime} d t$ to independently track the "mean" and "faster than average" pathways to autoignition of the unburnt mixture. Heat released by AI is alternatively activated for the two transported integrals to avoid mutual interference. Knock intensities $(K I \mathrm{~s})$ associated to each knocking event are then calculated using the estimated MAPO function [23] (eMAPO, Eq. (4)), defined as the pressure rise corresponding to the instantaneous combustion of the remaining unburnt fuel at knock onset (KO). In Eq. (4), $p_{K O}$ is the in-cylinder pressure at $\mathrm{KO}, Q_{A I}$ is the heat produced by auto-ignition, $m_{c y l}$ is the in-cylinder gas mass, $T_{K O}$ is the unburned temperature at $\mathrm{KO}$, while $c_{p}, M W$ and $R_{u}$ are the specific heat, the molecular weight of the unburned mixture and the universal molar gas constant.

$$
e M A P O=p_{K O} \frac{Q_{A I}}{m c y l \cdot T_{K O}\left(c_{p}-\frac{R_{u}}{M W}\right)}
$$

A maximum allowable $e M A P O\left(e M A P O_{\max }\right)$ as in the experiments $\left(e M A P O_{\max }=2\right.$ bar in the specific case reported in the paper) is then set for the sake of consistency. The $e M A P O \mathrm{~s}$ associated to the two transported $\mathrm{LW}$ distributions, hereafter referred to as $e M A P O_{A V E R}$ and $e M A P O \mathrm{n}$ are then used to reconstruct a log-normal distribution of $K I$. Finally, the associated CDF is used to estimate the knock probability below/above the eMAPOmax limit:

$$
C D F(x)=\frac{1}{2} \cdot\left[1+\operatorname{erf}\left(\frac{\ln x-\mu}{\sigma \cdot \sqrt{2}}\right)\right]
$$

where $\mu$ and $\sigma$ are the mean and the standard deviation of $\ln (\mathrm{x})$. 


\section{3D-CFD model}

A 3D model of the engine is built using a customized version of STAR-CD v4.30, licensed by SIEMENS DISW. As shown in Figure 2, symmetry is exploited to reduce the computational effort, thanks to the use of a RANS modelling framework. As discussed in [11] the GDI optical unit under investigation features a non-negligible crevice volume which is included in the CFD model to account for compression ratio reduction and blow-by losses. The global average mesh size is around $0.8 \mathrm{~mm}$, so that fluid cells range from 1.2 million at BDC to 0.4 million at TDC. Engine speed is 2000 RPM, while start of injection is triggered at $300 \mathrm{CA}$ bTDC with a single-pulse strategy at a pressure equal to $100 \mathrm{bar}$. The overall airto-fuel ratio is slightly lean $(\lambda \approx 1.1)$. The $\mathrm{k}-\varepsilon \mathrm{RNG}$ model is used for turbulence. A calibrated 1D model of the engine is used to impose time varying pressure and temperature boundary conditions at both the intake and the exhaust port.

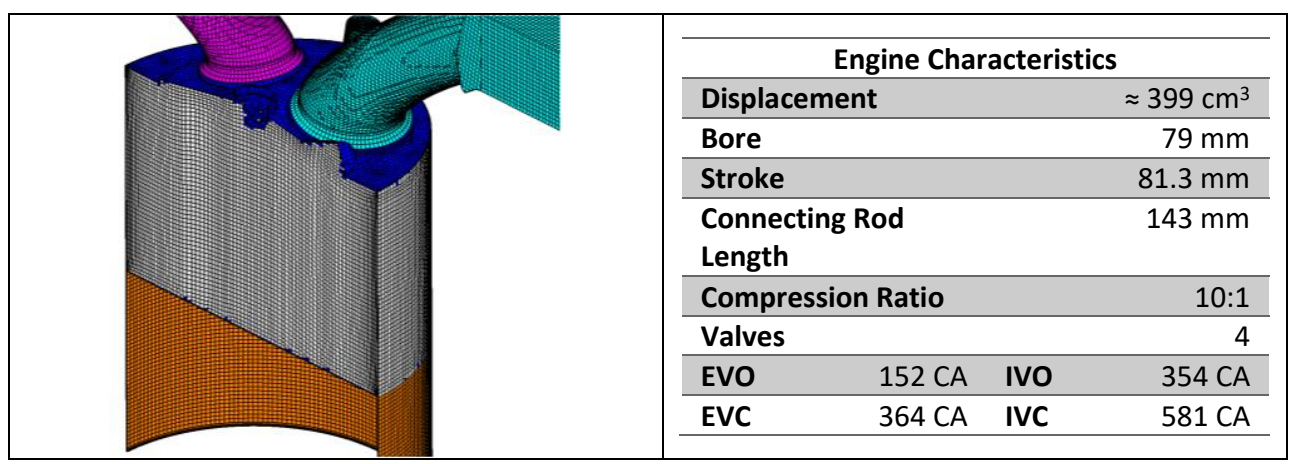

Figure 1: Computational grid and geometric engine characteristics.

An additional mass flow rate is applied at the annular area at the bottom of the crevice to model blow-by losses. Uniform wall temperatures are applied at each engine component facing the combustion chamber and the GruMo-UniMore wall heat transfer model $[24,25$, $26,27,28]$ is used to estimate wall heat transfer. The ECFM-3Z combustion model is adopted [29], integrated by a user-defined correlation for laminar flame speed following the approach described in $[2,30,12,7]$. The stratification of fresh charge has a key role in the simulation [5,31]. To reduce modelling uncertainties, a high degree of accuracy in describing the sixhole full-cone spray evolution is required. Therefore, the spray is modelled following the approach described in $[32,33,34]$ for multi-hole GDI injectors. Finally spark timing is set at 15 CA BFTDC, hereafter SA15. Figure 3 shows in-cylinder pressure history of 200 consecutive cycles and their ensemble average. The 3D-CFD pressure trace is added to confirm the robustness of the adopted numerical framework. 


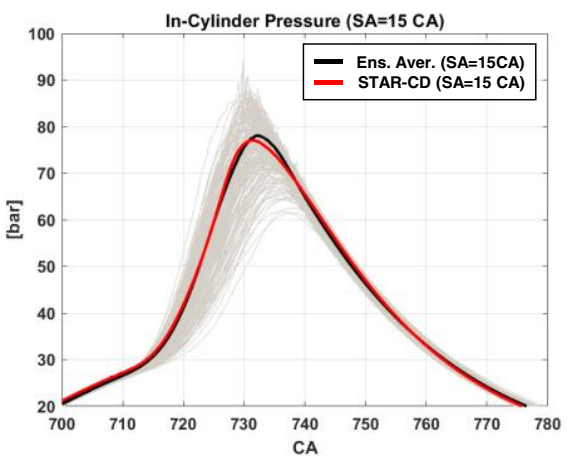

Figure 2: Cycle-resolved in-cylinder pressure from the experimental dataset (grey thin lines), experimental ensemble average (black line) and RANS pressure trace (red line).

\section{Results}

The following section reports the most relevant results of the proposed preliminary analysis. It is split in three macro areas. Firstly, attention is focused on the comparison of the autoignition delay maps of the different surrogates. Secondly, attention is shifted to the analysis of knock statistics. Thirdly, outcomes are discussed in the light of the blend specific $O I$.

A comparison between autoignition delay maps is firstly reported in Figure 4. In particular, maps are depicted in terms of percentage variations with reference to the RON95-MON85 $(S=10)$ surrogate. Secondly, the statistical knock tendencies for the five proposed surrogates, as expressed by the eMAPO distributions, are reported in Figure 5. Fuels with equal sensitivity show very similar distributions, while larger differences can be observed when decreasing the sensitivity. Such evidence confirms the previous observations in terms of autoignition delay maps. In particular, BS5 predicts a percentage of "knocking cycles" (i.e. cycles exceeding the eMAPO threshold of 2 bar) close to $45 \%$, while high-sensitivity blends (namely BS10, BS10-B and BS10-C) exhibit values around 13 to $6 \%$. Such value is closer to the experimental evidence, which was measured using a commercial RON95 European gasoline with sensitivity of 10 . Thirdly, the analysis is shifted towards the correlation between knock onset and $O I$ of a given surrogate. In particular, Figure 6 shows two distinct values of knock onset crank angles for each fuel, one related to the average knock precursor (blue line) and the other to the faster-than-average knock precursor (red line). In view of the almost rigid shift between the knock onset angles, the red line is here discussed for the sake of brevity.

Two contradictory observations emerge from Figure 6. On the one side, comparing BS5, BS7.5 and BS10 it is possible to see the effect of octane sensitivity on equal RON: the increase of $O I$ for increasing $S$ reduces the attitude of the engine to auto-ignite. This confirms the need to go beyond $R O N$ to assess the anti-knock fuel characteristics and it suggests $O I$ as a valid knock-tendency estimator. On the other side, comparing BS7.5 ( $S=7.5 ; O I=$ $100.92)$ and BS10-C ( $S=10, O I=97.89)$ which exhibit large differences in $O I$, one would expect a stronger attitude towards knock for the former while 3D-CFD analyses indicate that the most knock-prone is the latter. Therefore, $O I$ seems to fail in correctly representing the fuel propensity to auto-ignite. Such discrepancy can be explained observing Figure 7, where 
ignition delay times (IDT) for a temperature sweep are reported at 50bar, $\lambda=1.1$ and $\mathrm{EGR} \%=0$. As visible, in contrast to $O I$, BS10-C shows slightly longer delays than BS7.5. Such slight difference is visible also in Figure 7 [B], where the ratio between the ignition delays is reported for a wider range of pressures and for a fixed value of $\lambda$ together with the $p-T_{u}$ engine history. The two surrogates shown nearly equivalent reactivities despite different values of $S$ and $O I$. This seems to suggest that $O I$ as a standalone metrics for knock propensity provides consistent results only either comparing fuels blends on equal sensitivity $S$ value or comparing fuel blends on equal of $R O N$.

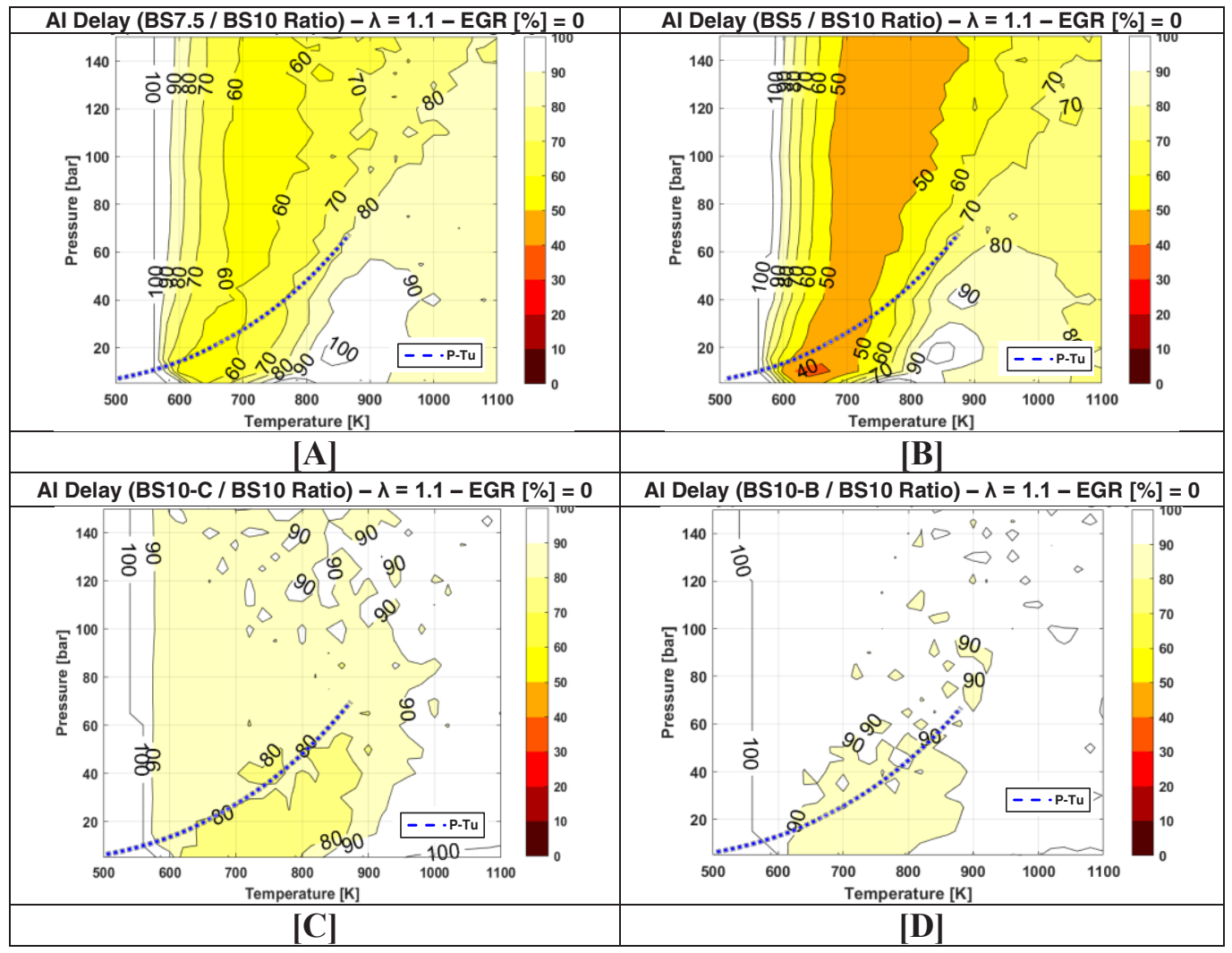

Figure 4: Blend reactivity comparison. 
Percentage Distribution of safe Cycles

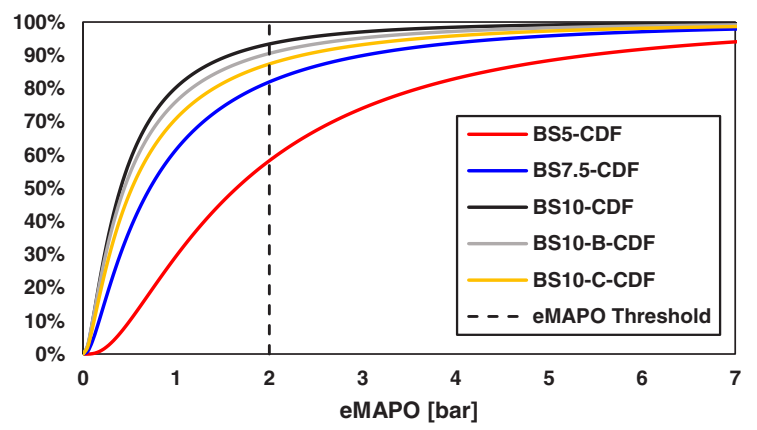

Figure 5: Statistical distribution of eMAPO and its cumulative distribution for all of surrogates formulations varying the octane sensitivity $(S)$.

\begin{tabular}{|l|ccc|c|}
\hline \multicolumn{5}{|c|}{ BLEND REACTIVITY PARAMETERS } \\
\hline BLEND & RON & MON & S & OI \\
\hline BS5 & 95 & 90 & 5 & 98.95 \\
BS7.5 & 95 & 87.5 & 7.5 & 100.92 \\
BS10 & 95 & 85 & 10 & 102.89 \\
\hline BS10-B & 92.5 & 82.5 & 10 & 100.39 \\
BS10-C & 90 & 80 & 10 & 97.89 \\
\hline
\end{tabular}

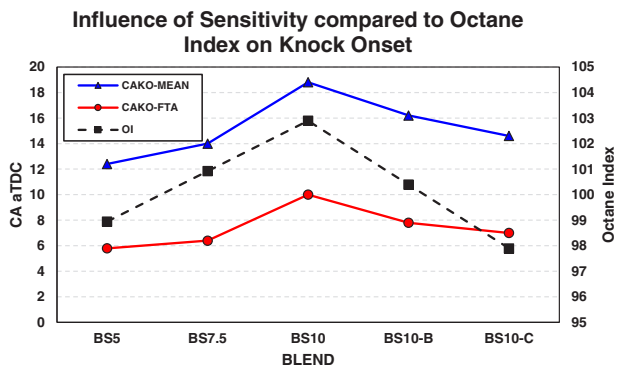

Figure 6: Predicted CA knock onset for each surrogates, compared with their Octane Index

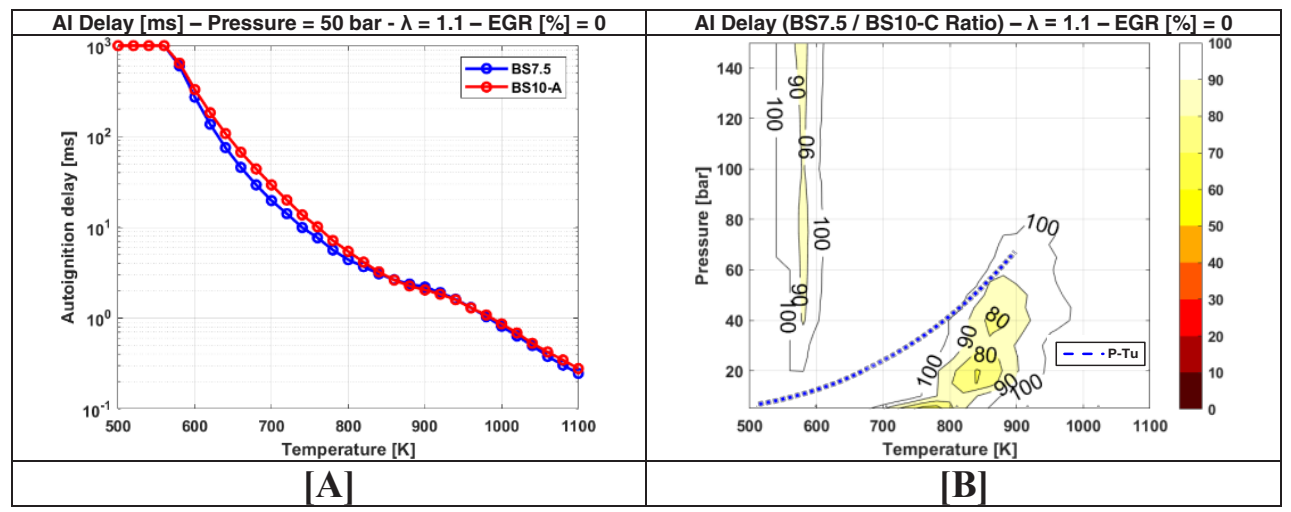

Figure 7: [A] IDT for a fixed values of $\mathrm{P}$ and $\Phi$ in a wide range of Tu for both BS7.5 and BS10-C.

$[B]$ Reactivity ratio between both surrogates at fixed $\Phi$ compared with p-Tu trace. 


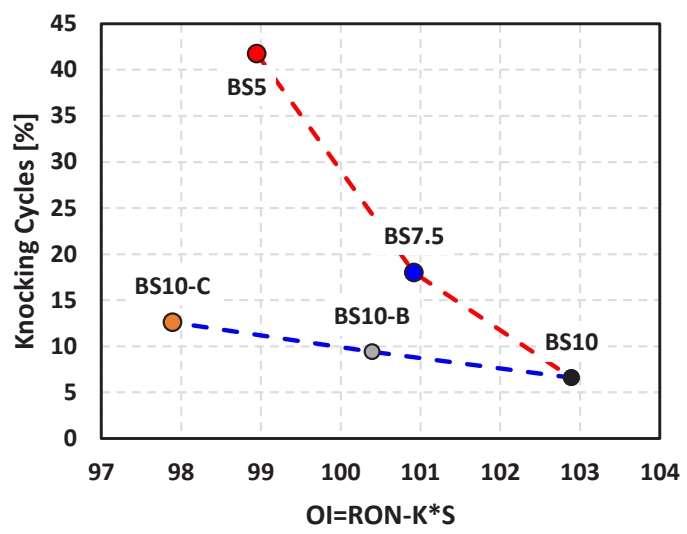

Figure 8: Representation of the percentage of the cycles exceeding the eMAPO threshold of 2 bar compared to the different surrogates octane index.

Figure 8 summarizes the above statements showing the two distinct trends on equal $S$ and $R O N$. Nevertheless, due to the limited number of investigated cases, it is at present difficult to formulate a more consistent index able to overcome the limitation discussed earlier. Future studies on a wider range of blends possibly built using a larger number of components will be aimed at formulating a more comprehensive index able to synthetize the knock propensity of a given fuel blend.

\section{Conclusion}

A preliminary study on the influence of Octane Sensitivity on knock statistics was presented. To this aim, attention was paid to the definition and characterization of representative gasoline surrogates using simplified TRF blends. To simplify the preliminary study, the authors chose five formulations alternatively varying octane sensitivity $S$ on equal $R O N$ and $R O N$ on equal $S$. Firstly, a chemical kinetics-driven analysis of mixture reactivity was carried out using constant pressure reactors to build up Look-Up tables of ignition delay times. Secondly, tables were then used in 3D-CFD simulations of a single cylinder research engine for which a calibrated numerical framework was developed by the authors in previous studies. In particular, a proprietary statistical knock model was used to infer the statistical probability of knocking cycles. Thirdly and finally, the correlation between 3D-CFD outcomes and the Octane Index OI proposed by Kalghatgi was investigated. Results shows a twofold correlation between $O I$ and knocking frequency (i.e. percentage of knocking cycles) with different trends being exhibited by fuels varying $S$ on equal $R O N$ and varying $R O N$ on equal $S$. As stated earlier, the limited number of investigated cases suggests that future studies will be needed to build a wider database of fuel blends and recipes with the final goal to formulate a comprehensive index able to characterize the knock propensity of a given fuel. 


\section{Reference}

[1]. Heywood JB. Internal Combustion Engine Fundamentals. McGraw-Hill, 1988.

[2]. Sarathy SM, Farooq A, Kalghatgi GT. Recent progress in gasoline surrogate fuels. Prog. Energy Combust. Sci. 2018;65:67-108. https://doi.org/10.1016/j.pecs.2017.09.004.

[3]. Kalghatgi GT. Auto-ignition quality of pratical fuels and implications for fuel requirements of future SI and HCCI engines. SAE Technical Paper 2005-010239

[4]. Kalghatgi GT. Fuel Anti-Knock Quality-Part II. Vehicle Studies-How Relevant in Motor Octane Number in modern engines? SAE paper 2001-01-3585, 2001. https://doi.org/10.4271/2001-01-3585

[5]. Bozza F, Fontanesi S, Gimelli A, Severi E, Siano D. Numerical and Experimental Investigation of Fuel Effects on Knock Occurrence and Combustion Noise in a 2-Stroke Engine. SAE Int. J. Fuels Lubr. 2012;5(2):674695. https://doi.org/10.4271/2012-01-0827

[6]. Shekhawat Y, Haworth DC, d'Adamo A, Berni F, Fontanesi S, Schiffmann P et al. An Experimental and Simulation Study of Early Flame Development in a Homogeneous-charge Spark-Ignition Engine. Oil Gas Sci. Technol. - Rev. IFP 2017;72(5):32. https://doi.org/10.2516/ogst/2017028

[7]. Del Pecchia M, Pessina V, Berni F, d'Adamo A, Fontanesi S. Gasoline-ethanol blend formulation to mimic laminar flame speed and auto-ignition quality in automotive engines. Fuel 264, 116741, 2020. https://doi.org/10.1016/j.fuel.2019.116741

[8]. D'Adamo A, Breda S, Iaccarino S, Berni F, Fontanesi S, Zardin B et al. Development of a RANS-Based Knock Model to Infer the Knock Probability in a Research Spark-Ignition Engine. SAE Int. J. Engines 10(3):722-739, 2017, https://doi.org/10.4271/2017-01-0551

[9]. Fontanesi S, Cicalese G, d'Adamo A, Cantore G. A Methodology to Improve Knock Tendency Prediction in High Performance Engines. Energy Procedia 45:768-778, 2014. https://doi.org/10.1016/j.egypro.2014.01.082

[10]. Breda S, d'Adamo A, Fontanesi S, D'Orrico F, Irimescu A, Merola S et al. Numerical Simulation of Gasoline and n-Butanol Combustion in an Optically Accessible Research Engine. SAE Int. J. Fuels Lubr. 10(1):32-55, 2017, https://doi.org/10.4271/2017-01-0546

[11]. Del Pecchia M, Fontanesi S. A methodology to formulate multicomponent fuel surrogates to model flame propagation and ignition delay. Fuel 2020;279:118337. https://doi.org/10.1016/j.fuel.2020.118337

[12]. Del Pecchia M, Sparacino S, Pessina V, Fontanesi S, Breda S, Irimescu A et al. Development of a Sectional Soot Model Based Methodology for the Prediction of Soot Engine-Out Emissions in GDI Units. SAE Technical Paper 2020-010239, 2020, doi:10.4271/2020-01-0239

[13]. Sarathy SM, Kukkadapu G, Mehl M, Javed T, Ahmed A, et al. (2016) Compositional effects on the ignition of FACE gasolines. Combustion and Flame 169: 171-193. Available: http://dx.doi.org/10.1016/j.combustflame.2016.04.010 
[14]. Fontanesi S, Paltrinieri S, Tiberi A, d'Adamo A. LES Multi-cycle Analysis of a High Performance GDI Engine. SAE Technical Paper 2013-01-1080, 2013. https://doi.org/10.4271/2013-01-1080

[15]. Fontanesi S, d'Adamo A, Paltrinieri S, Cantore G, Rutland CJ. Assessment of the Potential of Proper Orthogonal Decomposition for the Analysis of Combustion CCV and Knock Tendency in a High Performance Engine. SAE Technical Paper 2013-24-0031, 2013. https://doi.org/10.4271/2013-24-0031

[16]. d'Adamo A, Breda S, Berni F, Fontanesi S. Understanding the Origin of Cycleto-Cycle Variation Using Large-Eddy Simulation: Similarities and Differences between a Homogeneous Low-Revving Speed Research Engine and a Production DI Turbocharged Engine. SAE Int. J. Eng. 2019;12(1):79-100. https://doi.org/10.4271/03-12-01-0007

[17]. Krastev VK, d'Adamo A, Berni F, Fontanesi S. Validation of a zonal hybrid URANS/LES turbulence modeling method for multi-cycle engine flow simulation. Int. J. Engine Res. 2020;21(4):632-648. https://doi.org/10.1177/1468087419851905

[18]. Rulli F, Barbato A, Fontanesi S, d'Adamo A. Large eddy simulation analysis of the turbulent flow in an optically accessible internal combustion engine using the overset mesh technique. Int. J. Engine Res. 2021;22(5):1440-1456. https://doi.org/10.1177/1468087419896469

[19]. Iacovano C, Zeng Y, Anbarasu M, Fontanesi S, d'Adamo A. Validation of a LES Spark-Ignition Model (GLIM) for Highly-Diluted Mixtures in a Closed Volume Combustion Vessel. SAE Technical Paper 2021-01-0399, 2021. https://doi.org/10.4271/2021-01-0399

[20]. Fontanesi S, Cicalese G, Cantore G, d'Adamo A. Integrated In-Cylinder/CHT Analysis for the Prediction of Abnormal Combustion Occurrence in Gasoline Engines. SAE Technical Paper 2014-01-1151, 2014. https://doi.org/10.4271/2014-01-1151.

[21]. d'Adamo A, Breda S, Fontanesi S, Irimescu A, Merola SS, Tornatore C. A RANS knock model to predict the statistical occurrence of engine knock. Appl. Energy 2017;191:251-263. https://doi.org/10.1016/j.apenergy.2017.01.101

[22]. Livengood JC, Wu PC. Correlation of autoignition phenomena in internal combustion engines and rapid compression machines. Symp Int Combust 1955; 5: 347-356

[23]. d'Adamo A, Breda S, Berni F, Fontanesi S. The potential of statistical RANS to predict knock tendency: Comparison with LES and experiments on a sparkignition engine" Appl. Energy 2019;249:126-142 https://doi.org/10.1016/j.apenergy.2019.04.093M

[24]. Berni F, Fontanesi S. A 3D-CFD methodology to investigate boundary layers and assess the applicability of wall functions in actual industrial problems: A focus on in- cylinder simulations. Appl. Therm. Eng. 174, 115320, 2020. https://doi.org/10.1016/j.applthermaleng.2020.115320

[25]. Berni F, Cicalese G, Borghi M, Fontanesi S. Towards grid-independent 3D-CFD wall-function-based heat transfer models for complex industrial flows with focus on in-cylinder simulations. Appl. Therm Eng. 2021; 190, 116838. https://doi.org/10.1016/j.applthermaleng.2021.116838. 
[26]. Iacovano C, d'Adamo A, Fontanesi S, Di Ilio G, Krastev VK. Application of a zonal hybrid URANS/LES turbulence model to high and low-resolution grids for engine simulation. Int. J. Engine Res. 2020. doi:10.1177/1468087420931712

[27]. Berni F, Fontanesi S, Cicalese G, d'Adamo A. Critical Aspects on the Use of Thermal Wall Functions in CFD In-Cylinder Simulations of Spark-Ignition Engines. SAE Int. J. Commer. Veh. 2017;10(2):547-561. https://doi.org/10.4271/2017-01-0569

[28]. Fontanesi S, Cicalese G, d'Adamo A, Pivetti G. Validation of a CFD Methodology for the Analysis of Conjugate Heat Transfer in a High Performance SI Engine. SAE Technical Paper 2011-24-0132, 2011. https://doi.org/10.4271/2011-24-0132

[29]. Colin O, Benkenida A. The 3-Zone Extended Coherent Flame Model (ECFM3Z) for computing premixed/diffusion combustion, Oil Gas Sci. Technol. - Rev. IFP 59(6):593-609, 2014. https://doi.org/10.2516/ogst:2004043

[30]. Del Pecchia M, Breda S, d'Adamo A, Fontanesi S, Irimescu A, Merola SS. Development of Chemistry-Based Laminar Flame Speed Correlation for PartLoad SI Conditions and Validation in a GDI Research Engine. SAE Int. J. Engines 2018;11(6):715-741. https://doi.org/10.4271/2018-01-0174

[31]. Breda S, d'Adamo A, Fontanesi S, Giovannoni N, Testa F, Irimescu A, et al. CFD Analysis of Combustion and Knock in an Optically Accessible GDI Engine. SAE Int. J. Engines 2016;9(1):641-656. https://doi.org/10.4271/201601-0601

[32]. Sparacino S, Berni F, d'Adamo A, Krastev VK, Cavicchi A, Postrioti L. Impact of the Primary Break-Up Strategy on the Morphology of GDI Sprays in 3D-CFD Simulations of Multi-Hole Injectors. Energies. 2019;12(15):2890. https://doi.org/10.3390/en12152890

[33]. Sparacino S, Berni F, Cavicchi A, Postrioti L. Impact of different droplets size distribution on the morphology of GDI sprays: Application to multi-hole injectors. AIP Conference Proceedings 2191, 020139, 2019. https://doi.org/10.1063/1.5138872

[34]. Malaguti S, Cantore G, Fontanesi S, Lupi R, Rosetti A. CFD Investigation of Wall Wetting in a GDI Engine under Low Temperature Cranking Operations. SAE Technical Paper 2009-01-0704, 2009. https://doi.org/10.4271/2009-01$\underline{0704}$ 